\title{
Diagnostic and prognostic values of C-X-C motif chemokine ligand 3 in patients with colon cancer
}

\author{
GUO-TIAN RUAN $^{1 *}$, YI-ZHEN GONG $^{1 *}$, XI-WEN LIAO $^{2}$, SHUAI WANG $^{1}$, WEI HUANG ${ }^{1}$, \\ XIANG-KUN WANG ${ }^{2}$, GUANG-ZHI ZHU ${ }^{2}$, CUN LIAO $^{1}$ and FENG GAO ${ }^{1}$ \\ Departments of ${ }^{1}$ Colorectal and Anal Surgery, and ${ }^{2}$ Hepatobiliary Surgery, \\ The First Affiliated Hospital of Guangxi Medical University, Nanning, Guangxi 530021, P.R. China
}

Received February 17, 2019; Accepted August 1, 2019

DOI: $10.3892 /$ or.2019.7326

\begin{abstract}
The diagnostic and prognostic mechanisms of $\mathrm{C}-\mathrm{X}-\mathrm{C}$ motif chemokine ligand 3 (CXCL3) in colon cancer (CC) have not yet been reported. Therefore, the objective of the present study was to use cohorts of patients from Guangxi Medical University and the Gene Expression Omnibus (GEO) database to investigate and validate CXCL3 for the diagnosis and prognosis of $\mathrm{CC}$, and to explore its prospective molecular mechanism. Reverse transcription-quantitative PCR (RT-qPCR) analysis of 38 paired tumor and non-tumor tissues, and immunohistochemistry (IHC) of 212 tumor and 46 non-tumor tissues was conducted to explore the expression of $C X C L 3$ and its diagnostic and prognostic significance in the Guangxi Medical University CC cohort. A GEO dataset, GSE40967, was used to validate the prognostic significance of $C X C L 3$. Gene set enrichment analysis (GSEA) was also conducted to explore the potential molecular mechanisms underlying the effects of CXCL3 in CC. The RT-qPCR results indicated that $C X C L 3$ expression was significantly higher in cancer tissues compared with adjacent normal tissues, suggesting that it may have high diagnostic value for CC. Multivariate Cox analysis based on the IHC results suggested that there was no appreciable association between CXCL3 positivity and the overall survival (OS) time of CC. However, a stratified analysis revealed that high expression of CXCL3 was associated with considerably increased mortality in the subgroup of CC patients with tumor size $<5 \mathrm{~cm}$ (adjusted $\mathrm{P}=0.042$, adjusted $\mathrm{HR}=2.298,95 \% \mathrm{CI}=1.030-5.126)$ and with tumor thrombus (adjusted $\mathrm{P}=0.019$, adjusted $\mathrm{HR}=5.096$,
\end{abstract}

Correspondence to: Professor Feng Gao, Department of Colorectal and Anal Surgery, The First Affiliated Hospital of Guangxi Medical University, 6 Shuangyong Road, Nanning, Guangxi 530021, P.R. China

E-mail: doctor0771@163.com

*Contributed equally

Key words: C-X-C motif chemokine ligand 3, colon cancer, diagnosis, prognosis, GSE40967
95\% CI=1.306-19.886). In the GSE40967 dataset, high expression of CXCL3 was closely associated with poor OS in CC (adjusted $\mathrm{P}=0.049$, adjusted $\mathrm{HR}=1.416,95 \% \mathrm{CI}=1.002-2.003$ ). Furthermore, GSEA indicated that the high expression of CXCL3 was closely associated with DNA repair, cell cycle process, cell apoptosis process and the $P 53$ regulation pathway. In summary, these result suggest that $C X C L 3$ might serve as a novel biomarker in the diagnosis and prognosis of $\mathrm{CC}$.

\section{Introduction}

Colorectal cancer (CRC) includes malignant tumors that occur in the colon, rectum and anus. With its high morbidity and mortality, CRC is among the most malignant tumors worldwide. It has been estimated that there were $>1.8$ million new CRC cases and 880,000 CRC-associated deaths in 2018, accounting for approximately one-tenth of all cancer cases and deaths. Among all cancers worldwide, CRC ranks third in terms of morbidity and second in terms of mortality (1). In China, $\mathrm{CRC}$ has high incidence and mortality, and is one of the top five most commonly diagnosed tumors (2). The leading cause of mortality for patients with CRC is metastasis. The 5 year overall survival (OS) rate of patients with primary CRC can be as high as $80-90 \%$, but this may be reduced to $5-10 \%$ in patients with metastatic tumors $(3,4)$. Like many other cancers, CRC is a heterogeneous disease in which genetic variation, cellular context and environmental effects have an impact on the initiation, progression and metastasis of tumors (5). Accordingly, it is highly crucial to locate biomarkers and prognostic indicators for the early detection of malignant cell transformation.

The use of whole-genome data to screen for markers of tumors, which can be applied to diagnosis and prognosis, is efficient and effective and can be used to guide the exploration of prospective mechanisms. The Gene Expression Omnibus (GEO) is the most comprehensive, well known and largest international public database for the storage and query of expression data; it is developed and maintained by the National Center for Biotechnology Information. Its purpose is to provide a good platform for post-data mining and information promotion by collecting a large amount of high-throughput experimental data (6).

The gene $\mathrm{C}-\mathrm{X}-\mathrm{C}$ motif chemokine ligand 3 (CXCL3), a member of the $\mathrm{CXC}$ chemokine family, encodes a secreted 
growth factor that signals through the $\mathrm{G}$ protein-coupled receptor $\mathrm{CXC}$ receptor 2 , and thereby serves a role in inflammation and acts as a chemoattractant of neutrophils $(7,8)$. Previous studies have investigated the prognostic relationship between CXCL3 and CRC. The study by Doll et al (9) identified no significant correlation between CXCL3 expression and CRC survival, whereas the findings of Xiong et al (10) suggested that CRC patients with high CXCL3 expression levels had a shorter OS time. More than $50 \%$ of CRCs are colon cancer (CC) (1); CC and rectal cancer have different causes $(11,12)$, and their pathogenesis and histological types also differ. In the study conducted by Xiong et al (10), patients with colon and rectal cancer from a TCGA dataset were combined for the prognostic analysis of $C X C L 3$; however, as patients with colon and rectal cancer are two separate cohorts, the results require further investigation. Furthermore, the study lacked analysis at the protein level. Therefore, the aim of the present study was to use a patient cohort from Guangxi Medical University and a GEO dataset to investigate and validate $C X C L 3$ for the diagnosis and prognosis of $\mathrm{CC}$, and to explore its prospective molecular mechanism.

\section{Materials and methods}

Reverse transcription-quantitative PCR (RT-qPCR) of CXCL3 expression in CC tissue

Patient tissue samples and ethical approval. From April to June 2018, cancer and adjacent normal tissues were continuously collected during the resective surgery of patients with CC in the Department of Colorectal and Anal Surgery, First Affiliated Hospital of Guangxi Medical University (Nanning, Guangxi). Immediately after surgery, the tissue was smeared in RNA protection solution and stored in refrigerator at $-80^{\circ} \mathrm{C}$. The inclusion criteria for patients were as follows: i) Without restrictions of age and sex; ii) underwent resection of colon tumor; and iii) with a pathological diagnosis of colon cancer. The exclusion criteria include: i) Complicated with other known tumors; ii) received radiotherapy or chemotherapy prior to surgery; iii) refused to provide written informed consent; iv) the tumor was too small for a specimen to be acquired. The study was conducted in accordance with the Declaration of Helsinki, all patients signed an informed consent form, and the Ethics Committee of the First Affiliated Hospital of Guangxi Medical University approved the experimental protocol [Ethics no.: 2019(KY-E-001)].

$R N A$ extraction and $R T-q P C R$. Total RNA was extracted from the patients' tissues using TRIzol reagent (cat. no. 15596026; Invitrogen, Thermo Fisher Scientific,Inc.). Then,PrimeScript ${ }^{\mathrm{TM}}$ RT Reagent kit with gDNA Eraser (cat. no. RR047A; Takara Bio, Inc.) was used to transform the total RNA into first-strand cDNA. The reverse transcription reaction conditions were as follows: $42^{\circ} \mathrm{C}$ for $60 \mathrm{~min}, 70^{\circ} \mathrm{C}$ for $5 \mathrm{~min}$, and $4^{\circ} \mathrm{C}$ until required. qPCR was then conducted using FastStart Universal SYBR Green Master (ROX) (Roche Diagnostics GmbH) in an Applied Biosystems QuantStudio ${ }^{\mathrm{TM}} 6$ Real-PCR System (Thermo Fisher Scientific, Inc.). All procedures were conducted in accordance with the manufacturer's instructions. The expression level of CXCL3 was calculated using the $2^{\triangle \triangle C q}$ method $(13,14)$, and was normalized to GAPDH expression.
The primer sequences were as follows: $C X C L 3$ forward, CCA AACCGAAGTCATAGCCAC and reverse, TGCTCCCCT TGTTCAGTATCT; GAPDH forward, GTCAGCCGCATC TTCTTT and reverse, CGCCCAATACGACCAAAT.

\section{Immunohistochemistry (IHC) of CXCL3 expression in CC tissue}

Patient tissue samples and ethical approval. Tumor tissue and adjacent normal tissue (slice thickness, $4 \mu \mathrm{m}$ ), fixed with $10 \%$ neutral formalin at room temperature for $16 \mathrm{~h}$ and embedded in paraffin wax blocks, were retrospectively collected from patients who had undergone colonic tumor resection in the First Affiliated Hospital of Guangxi Medical University between May 2012 and May 2013. The inclusion criteria for patients were as follows: i) Without restrictions of age and sex; ii) received resection of colon tumor; and iii) with a pathological diagnosis of colon cancer. The exclusion criteria include: i) Complicated with other known tumors; ii) received radiotherapy or chemotherapy prior to surgery; iii) refused to sign informed consent; iv) the tumor was too small for a specimen to be acquired. Tumors were identified and categorized according to the tumor node metastasis (TNM) staging system of the American Joint Committee on Cancer (8th edition, 2017) (15). Information about the patients was recorded as follows: Sex, age, preoperative carcinoembryonic antigen levels, TNM stage, tumor location, general classification, tumor differentiation, tumor thrombus, tumor size, tumor number, lymph node status, radical resection, tumor metastasis, nerve infiltration and postoperative chemotherapy. The study was conducted in accordance with the Declaration of Helsinki. Prior to the study, all patients received informed consent and ethical approval for the study was provided [Ethics no.: 2019(KY-E-001)].

Evaluation of IHC. IHC was applied for evaluation of the expression of CXCL3. A CXCL3 antibody (cat. no. \#35751) supplied by Signalway Antibody LLC, IHC staining reagents (DAB) and Secondary Antibody, HRP (cat. no. D-3004-15) from Shanghai ChangDao Biotech Co., Ltd. were used. Antigen retrieval was conducted using sodium citrate buffer for $2.5 \mathrm{~min}$ at high pressure, followed by cooling for $5 \mathrm{~min}$, and washing with PBS buffer for 3 min three times. The IHC procedure and steps were performed strictly following the manufacturers' protocols (incubation with primary antibody incubation at $1: 100$ dilution, $37^{\circ} \mathrm{C}$ for $2.5 \mathrm{~h}$; incubation with ready-to-use secondary antibody for $30 \mathrm{~min}$ at room temperature). The slides were observed under an Olympus upright microscope, white light (magnification x400). Two independent pathologists scored the average percentage of positive cells as follows: 0 (0\%); 1 (1-25\%); 2 (26-50\%); 3 (51-75\%); and $4(76-100 \%)$. The intensity of staining was scored as follows: 0 (negative); 1 (weak); 2 (moderate) and 3 (strong). The positive cell percentage was multiplied by the staining intensity score as previously described to provide the final pathological score, and a score $>2$ was considered to indicate a positive staining result (16).

Validation of CXCL3 expression in normal colon and colon tumor tissues. The expression level of CXCL3 in normal human tissues was obtained from Human Protein Atlas 
(HPA: https://www.proteinatlas.org, accessed December 22, 2018) (17). Expression levels of the CXCL3 gene in normal colon and primary tumor tissues were determined using the online tool GEPIA (http://gepia.cancer-pku.cn/detail. php?gene $=\mathrm{cxcl} 3$, accessed February 17, 2019) (18).

Validation cohort for the prognosis value of CXCL3 from the GEO database. A dataset of $C X C L 3$ gene expression values and corresponding clinical data was downloaded from the GEO database (https://www.ncbi.nlm.nih.gov/geo/query/acc. cgi?acc=GSE40967, accessed December 23, 2018) (19). The data were chosen according to the following inclusion criteria: i) Histopathological diagnosis of colon cancer; ii) primary tumor that could be surgically removed; iii) complete postoperative follow-up data; iv) all patients did not receive preoperative chemotherapy and/or radiation therapy; and v) number of cases $>500$. The exclusion criteria include: i) Complicated with other known tumors; ii) the subject of the study was not colon cancer; iii) sample size $\leq 500$. Since these datasets were obtained from public databases, their use did not need require ethical approval.

Gene set enrichment analysis (GSEA). For investigation of the prospective molecular mechanism of $C X C L 3$ in patients with a prognosis $\mathrm{CC}$, differential metabolic pathways and biological processes at the transcriptome level between high and low CXCL3 gene expression, which was based on the 75\% cut-off values, were analyzed using GSEA (http://software. broadinstitute.org/gsea/index.jsp, accessed December 24 , 2018) v3.0 (20). GSEA was used with reference to gene sets from the Molecular Signatures Database, namely c5 GO gene sets for biological process, cellular component and molecular function (c5.bp.v6.2.symbols.gmt, c5.cc.v6.2.symbols.gmt and c5.mf.v6.2.symbols.gmt) and c2 KEGG gene sets (c2.cp.kegg. v6.2.symbols.gmt). The number of permutations was set at 1,000. Enrichment results with one nominal P-value $<0.05$ and one false discovery rate (FDR) $<0.25$ were considered statistically significant.

Statistical analysis. The paired t-test was used to analyze the difference in the mRNA expression of CXCL3 between tumors and adjacent non-tumor tissues. $\chi^{2}$ test was used to compare the distribution of IHC staining scores between tumors and adjacent non-tumor tissues. The Kaplan-Meier method was performed for survival analysis. Cox proportional hazards regression analysis was applied to calculate the crude and adjusted hazard ratio (HR) and 95\% confidence interval (CI) in uni- and multivariate analyses. The FDR in GSEA was adjusted for multiple testing with the Benjamini-Hochberg procedure $(21,22)$. A scatter plot, receiver operating characteristic (ROC) curves and Kaplan-Meier survival curves were drawn using GraphPad Prism 7.0 (GraphPad Software, Inc.). $\mathrm{P}<0.05$ was considered statistically significant. SPSS v.24.0 software (IBM Corp.) was used to conduct the data analysis.

\section{Results}

RT-qPCR analysis of CXCL3 expression in CC tissue. RT-qPCR was performed on the $C C$ and adjacent normal tissue samples of 38 patients with CC. These CC patients ranged in age from 35 to 85 years, and included 25 men and 13 women. Analysis using a paired t-test demonstrated that the expression of $C X C L 3$ in cancer tissues was significantly higher than that in adjacent normal tissues $(\mathrm{P}=0.0004,95 \% \mathrm{CI}=0.052-0.164$; Fig. $1 \mathrm{~A}$ and $\mathrm{B}$ ). In addition, diagnostic ROC curve analysis indicated that $C X C L 3$ has a high diagnostic value for $\mathrm{CC}$ $(\mathrm{P}<0.0001, \mathrm{AUC}=0.896,95 \% \mathrm{Cl}=0.825-0.967$; Fig. $1 \mathrm{C})$.

IHC of CXCL3 expression in CC tissue. IHC testing was performed on another 212 tumor and 46 adjacent normal tissue samples, preserved in wax blocks, that were acquired from 212 patients with CC. The positive signaling of CXCL3, located in the cytoplasm of CC cells or adjacent normal colonic epithelium cells, was shown by the formation of a diffuse brown-yellow or dark-brown color following immunohistochemical staining (Fig. 2). Among the 212 cases of CC, 90 cases were CXCL3-positive (42.5\%), while positive CXCL3 expression was observed in only $4 / 46(8.7 \%)$ of the adjacent normal tissues.

Clinical and pathological factors that may be associated with prognosis were evaluated (Table I). A total of 137 male and 75 female patients, with an average age of 58 years were included in the evaluation. The median follow-up time after surgery was 1,934 days (range, 36-2,236 days); 10 patients were lost to follow-up. The positive rate of CXCL3 in cancer tissues was significantly higher than that in adjacent normal tissues $\left(\chi^{2}=20.536, \mathrm{P}<0.001\right.$; Fig. $\left.3 \mathrm{~A}\right)$ in the $46 \mathrm{CC}$ patients for which both types of tissue were available. The number of patients with IHC scores are shown in Fig. 3B. Diagnostic ROC curve analysis of CXCL3 revealed a moderate diagnostic value for $\mathrm{CC}(\mathrm{P}<0.0001, \mathrm{AUC}=0.785,95 \% \mathrm{Cl}=0.690-0.881$; Fig. 3C).

Univariate analysis revealed that advanced TNM stage, poorer tumor differentiation, tumor thrombus, lymph node positivity, non-radical resection and tumor metastasis were associated with poor outcomes (Table I). Kaplan-Meier analysis indicated that CXCL3 expression was not relevant to survival (Fig. 4A) and multivariate analysis showed that CXCL3 positive expression was not relevant to OS following adjustment for TNM stage, tumor differentiation, tumor thrombus and radical resection (adjusted $\mathrm{P}=0.934$, adjusted $\mathrm{HR}=1.022,95 \% \mathrm{CI}=0.604-1.729$ ).

Results of the stratified analysis of the association of CXCL3 with OS for different stratified clinical characteristics are displayed in Fig. 5. High expression of CXCL3 was significantly associated with an increased risk of death in the subgroups of patients with tumor size $<5 \mathrm{~cm}$ (adjusted $\mathrm{P}=0.042$, adjusted $\mathrm{HR}=2.298,95 \% \mathrm{CI}=1.030-5.126)$ and with tumor thrombus (adjusted $\mathrm{P}=0.019$, adjusted HR=5.096, 95\% CI=1.306-19.886).

Validation of CXCL3 expression in normal colon and colon tumor tissue. The expression level of CXCL3 in normal human tissues was obtained from the Human Protein Atlas. Data were extracted from the Functional Annotation of Mammalian Genomes 5 (FANTOM5) project, Genotype-Tissue Expression (GTEx) project and the HPA RNA-seq dataset (Fig. S1). Expression level analysis was performed for the CXCL3 gene in normal colon and colon tumor tissues. The expression of $C X C L 3$ in colon cancer tissues was significantly higher compared with that in normal colon tissues (Fig. S2). 

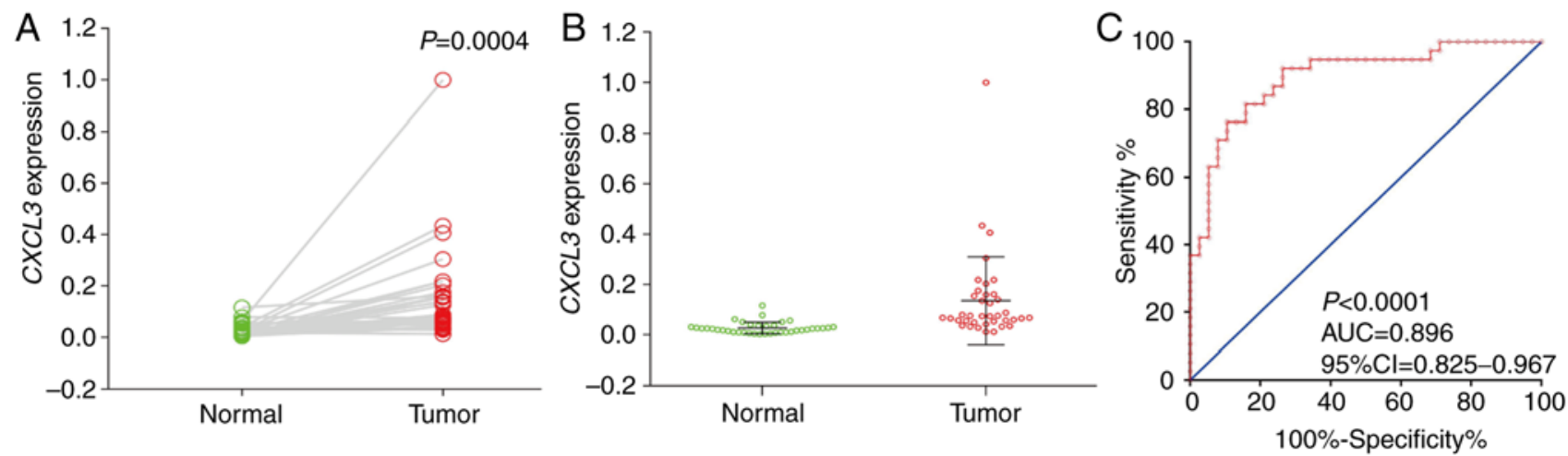

Figure 1. $C X C L 3$ mRNA expression in 38 paired samples from patients with $C \mathrm{C}$ and $\mathrm{ROC}$ analysis. (A) Paired comparison of $C X C L 3$ expression in cancer and adjacent tissues. (B) Comparison of $C X C L 3$ expression between tumor and normal tissues (the dots represent the expression levels of each sample, and the lines represent the median and quartiles). (C) ROC curve analysis. CXCL3, $C-X-C$ motif chemokine ligand 3; ROC, receiver operating characteristic; AUC, area under the curve.
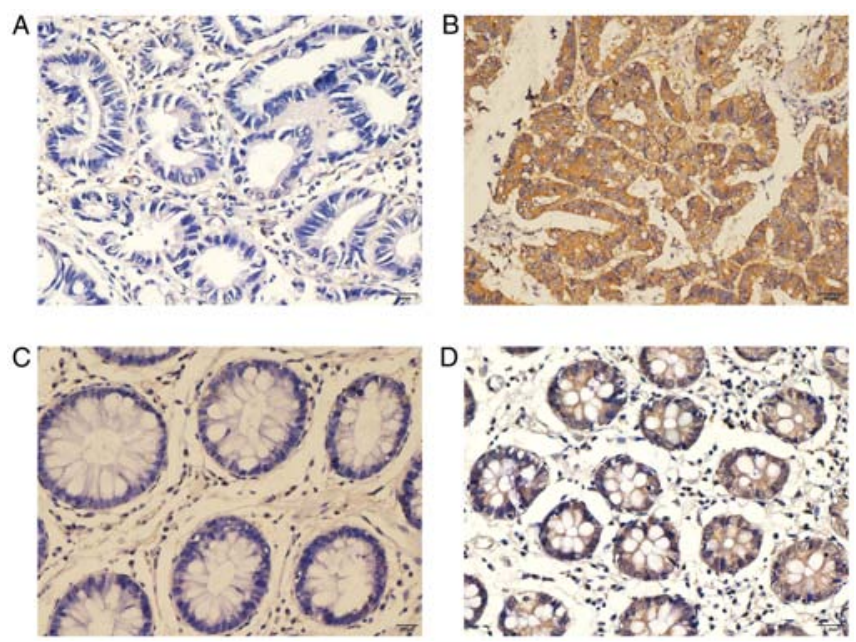

Figure 2. Immunohistochemical staining of CXCL3 in colon cancer. CXCL3 signaling was predominantly observed in the cytoplasm the cells. The positive immunohistochemical staining of $C X C L 3$ was shown as the formation of diffuse brown-yellow or dark-brown color. (A) Negative staining in colon tumor tissue, (B) positive expression in colon tumor tissue, (C) negative staining in adjacent normal tissue and (D) positive expression in adjacent normal tissues. CXCL3, C-X-C motif chemokine ligand 3.

Validation of the prognostic value of CXCL3 using the GEO database. The GPL570 expression profile chip data and clinical data were downloaded from the GSE40967 dataset. This included data for 585 patients. The sex, age (years), TNM stage, tumor location, adjuvant chemotherapy, mismatch repair (MMR) status, $\mathrm{CpG}$ island methylator phenotype status, chromosomal instability status, TP53 mutation, KRAS mutation, $B R A F$ mutation and Cartes d'Identité des Tumeurs (CIT) molecular subtype of these patients were collected.

The patients had a median age of 69 years (range, 22-97 years), and comprised 322 males and 263 females. In the GSE40967 CC cohort, it was observed that age $>65$ years, advanced TNM stage, KRAS mutations and the CIT molecular subtype $\mathrm{C} 4$ was associated with a significantly higher risk of $\mathrm{CC}$ death (Table II). Kaplan-Meier survival analysis with the $75 \%$ cut-off values of $C X C L 3$ expression suggested that CXCL3 expression in the GSE40967 cohort was not significantly associated with OS (Fig 4B). However, multivariate analysis indicated that high expression of CXCL3 (adjusted $\mathrm{P}=0.049$, adjusted $\mathrm{HR}=1.416,95 \% \mathrm{CI}=1.002-2.003$ ) was closely associated with poor OS in CC, after adjusting for age, TNM stage, KRAS gene and CIT subtypes.

Furthermore, the results of the stratified analysis of the association of CXCL3 with OS for different stratified characteristics are presented in Fig. 6. High expression of $C X C L 3$ was associated with a significantly increased risk of death in the following patient subgroups: Age $>65$ years (adjusted $\mathrm{P}=0.025$, adjusted $\mathrm{HR}=1.620,95 \% \mathrm{CI}=1.061-2.473)$, TNM stage $0-\mathrm{II}$ (adjusted $\mathrm{P}=0.014$, adjusted $\mathrm{HR}=1.839,95 \% \mathrm{CI}=1.132-2.989$ ), deficient MMR status (adjusted $\mathrm{P}=0.014$, adjusted $\mathrm{HR}=3.930$, 95\% CI=1.319-11.709), TP53 mutation (adjusted $\mathrm{P}=0.039$, adjusted $\mathrm{HR}=1.781,95 \% \mathrm{CI}=1.028-3.085)$, CIT molecular subtype $\mathrm{C} 4$ (adjusted $\mathrm{P}=0.010$, adjusted $\mathrm{HR}=4.134$, 95\% $\mathrm{CI}=1.398-12.219$ ) and male sex (adjusted $\mathrm{P}=0.026$, adjusted $\mathrm{HR}=1.628,95 \% \mathrm{CI}=1.059-2.504)$.

GSEA of CXCL3. GSEA of CXCL3 was also conducted in the GSE40967 cohort. The genome-wide expression profile dataset of the GSE40967 cohort was assorted into two categories in accordance with the $75 \%$ cut-off values of CXCL3 gene expression. GSEA results of the GSE40967 cohort are displayed in Figs. 7 and 8 and Tables SI and SII, and indicate that the high expression of CXCL3 exhibited appreciable relevance to DNA repair, cell cycle process, cell apoptosis process and the $P 53$ regulation pathway.

\section{Discussion}

The CXCL3 gene is located in a cluster of other CXC chemokines on chromosome 4 (23). It is a small cytokine belonging to the CXC chemokine family, and is also known as GRO3 oncogene, GRO protein gamma and macrophage inflammatory protein-2-beta $(7,8)$. CXC chemokines have a heparin-binding domain at the C-terminus of the molecule, that serve different roles in the regulation of angiogenesis (24). Simpson et al (25) reported that CXCL3 is widely expressed in the liver, and is involved in liver injury and inflammation; Luan et al (26) reported that CXCL3 is an important mediator of tumor initiation in human melanoma. Recent studies have shown that CXCL3 has significant functions in the progression 
Table I. Clinical and pathological parameters of 212 patients with colon cancer.

\begin{tabular}{|c|c|c|c|c|}
\hline Variable & No. of patients & MST (days) & $\mathrm{OS}^{\mathrm{a}}, \mathrm{HR}(95 \% \mathrm{CI})^{\mathrm{b}}$ & Log rank P-value \\
\hline Sex & & & & 0.801 \\
\hline Male & 137 & NA & 1 & \\
\hline Female & 75 & NA & $0.934(0.552-1.582)$ & \\
\hline Age (years) & & & & 0.536 \\
\hline$\leq 65$ & 137 & NA & 1 & \\
\hline$>65$ & 75 & NA & $1.174(0.707-1.950)$ & \\
\hline CEA (ng/ml) & & & & 0.169 \\
\hline $1-5$ & 113 & NA & 1 & \\
\hline$>5$ & 93 & NA & $1.424(0.858-2.363)$ & \\
\hline Missing & 6 & & & \\
\hline TNM stage & & & & $<0.0001$ \\
\hline I-II & 88 & NA & 1 & \\
\hline III-IV & 124 & NA & $5.049(2.563-9.945)$ & \\
\hline Location & & & & 0.806 \\
\hline Right & 102 & NA & 1 & \\
\hline Left & 109 & NA & $0.929(0.565-1.529)$ & \\
\hline Both & 1 & NA & $0\left(0-2.209 \times 10^{211}\right)$ & \\
\hline General classification & & & & 0.691 \\
\hline Invasive & 11 & NA & 1 & \\
\hline Ulcerative & 153 & NA & $1.511(0.367-6.221)$ & \\
\hline Mass & 42 & NA & $1.203(0.267-5.428)$ & \\
\hline Missing & 6 & & & \\
\hline Tumor differentiation & & & & 0.019 \\
\hline Well & 10 & NA & 1 & \\
\hline Moderately & 160 & NA & $1.451(0.352-5.993)$ & \\
\hline Poor & 42 & NA & $3.076(0.710-13.318)$ & \\
\hline Tumor thrombus & & & & $<0.0001$ \\
\hline No & 185 & NA & 1 & \\
\hline Yes & 26 & 660 & $4.571(2.568-8.134)$ & \\
\hline Missing & 1 & & & \\
\hline Tumor size (cm) & & & & 0.236 \\
\hline$<5$ & 90 & NA & 1 & \\
\hline$\geq 5$ & 116 & NA & $0.739(0.447-1.221)$ & \\
\hline Missing & 6 & & & \\
\hline Tumor number & & & & 0.138 \\
\hline One & 205 & NA & 1 & \\
\hline Two & 7 & 1,917 & $2.119(0.768-5.844)$ & \\
\hline Lymph node & & & & $<0.0001$ \\
\hline Negative & 120 & NA & 1 & \\
\hline Positive & 91 & NA & $3.546(2.075-6.061)$ & \\
\hline Missing & 1 & & & \\
\hline Radical resection & & & & $<0.0001$ \\
\hline Yes & 175 & NA & 1 & \\
\hline No & 37 & 481 & $11.536(6.836-19.469)$ & \\
\hline Tumor metastasis & & & & $<0.0001$ \\
\hline No & 179 & NA & 1 & \\
\hline Yes & 33 & 401 & $14.344(8.376-24.565)$ & \\
\hline Nerve infiltration & & & & 0.173 \\
\hline No & 207 & NA & 1 & \\
\hline Yes & 4 & 1,079 & $2.572(0.628-10.540)$ & \\
\hline Missing & 1 & & & \\
\hline
\end{tabular}


Table I. Continued.

\begin{tabular}{|c|c|c|c|c|}
\hline Variable & No. of patients & MST (days) & $\mathrm{OS}^{\mathrm{a}}, \mathrm{HR}(95 \% \mathrm{CI})^{\mathrm{b}}$ & Log rank P-value \\
\hline Postoperative chemotherapy & & & & 0.833 \\
\hline No & 69 & NA & 1 & \\
\hline Yes & 124 & NA & $1.061(0.610-1.846)$ & \\
\hline Missing & 19 & & & \\
\hline CXCL3 & & & & 0.730 \\
\hline Negative & 122 & NA & 1 & \\
\hline Positive & 90 & NA & $0.914(0.548-1.524)$ & \\
\hline
\end{tabular}

${ }^{a}$ OS times were available for 202 patients; ${ }^{b} \mathrm{HR}$ and $95 \%$ CI values were calculated using a univariate Cox proportional hazards regression model; ${ }^{~} \mathrm{P}$-values were calculated by the Kaplan-Meier method with a log-rank test. MST, median survival time; OS, overall survival time; TNM, tumor node metastasis; CEA, carcinoembryonic antigen; CXCL3, C-X-C motif chemokine ligand 3; NA, not available.
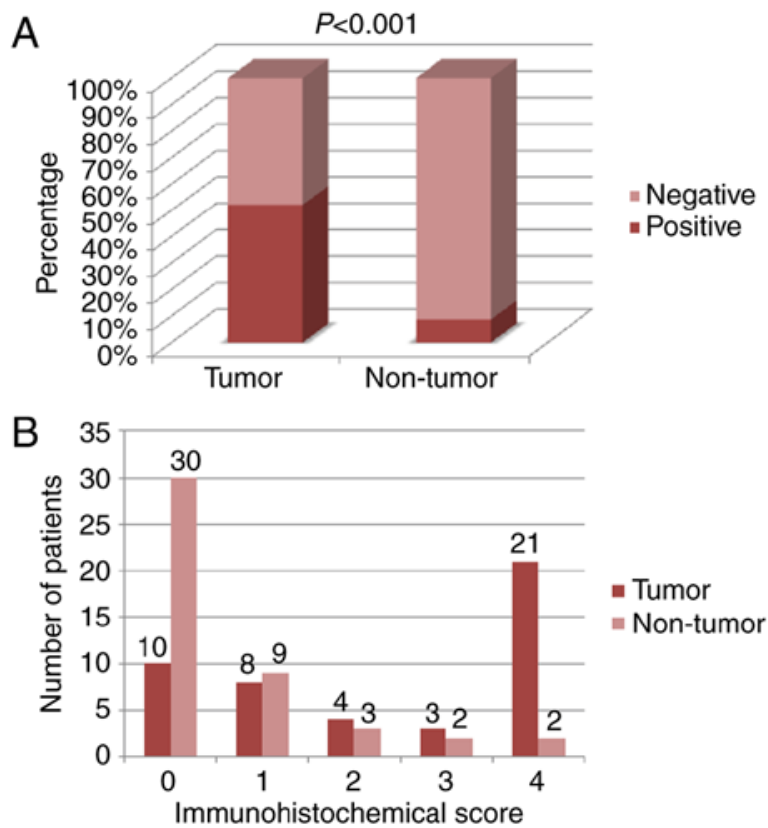

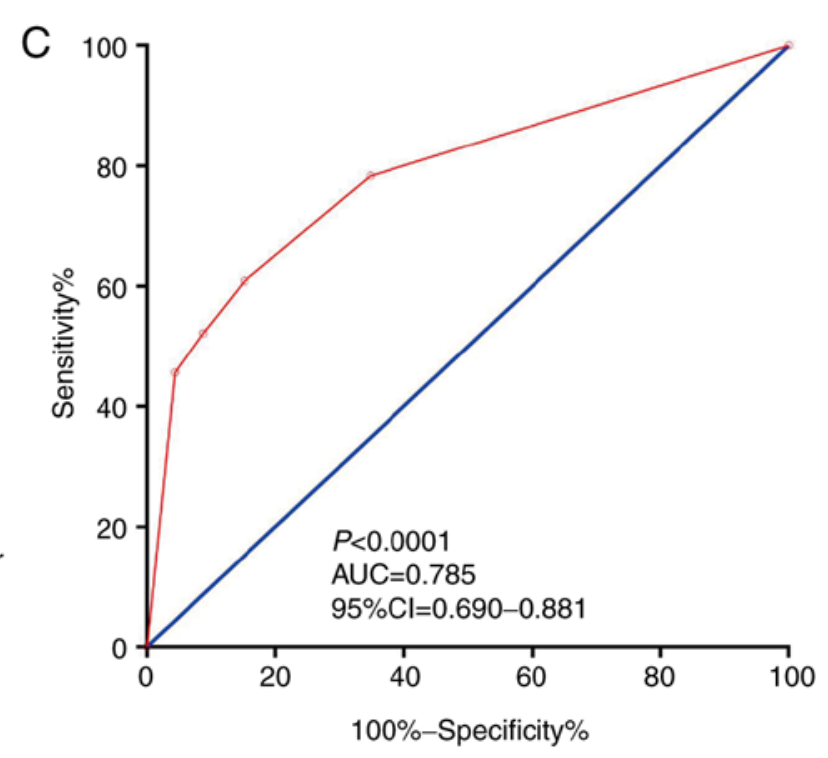

Figure 3. Immunohistochemical staining scores for CXCL3 in 46 pairs of tumor and adjacent normal tissues from patients with colon cancer, and ROC curve analysis. (A) Stacked column chart showing the positive and negative staining percentages of cancer and adjacent normal tissues. (B) Graph showing the immunohistochemical score distribution of $C X C L 3$. (C) ROC curve analysis. CXCL3, C-X-C motif chemokine ligand 3; ROC, receiver operating characteristic; AUC, area under the curve.

and metastasis of malignant tumors. See et al (27) reported that $C X C L 3$ is involved in breast cancer metastasis and may be a potential target for cancer treatment. Gui et al (28) suggested that $C X C L 3$ is overexpressed in prostate cancer and might play various roles in prostate cancer progression and metastasis. However, Li et al (29) found no significant difference in CXCL3 expression in non- and low-metastatic colon cancer cells, compared with highly metastatic colon cancer cells. Furthermore, Farquharson et al (30) demonstrated that insulin and adiponectin can participate in the occurrence of colon cancer through the regulation of CXCL3.

The study by Doll et al (9) showed that when CXCL3 mRNA expression was tested by RT-qPCR in the CRC tissues of 97 patients and normal colon tissues of 16 patients, CXCL3 gene expression was significantly increased in CRC compared with normal colon tissue. In the study by Xiong et al (10), the analysis of 695 RNA results from 645 CRC patients from the TCGA showed that the expression of CXCL3 in cancer tissues was considerably higher than that in adjacent normal tissues, which was verified by the RT-qPCR testing of 25 pairs of fresh CRC and adjacent noncancerous tissues collected from 25 patients at the First Affiliated Hospital of Chongqing Medical University. Similar results have also been found in other cancer studies; for example, one study found that CXCL3 was higher in early stage non-small cell lung cancer tissue as compared with the matched normal tissue (31). A meta-analysis also obtained comparable results for CXCL3 in breast cancer (27). In the present study, the analysis of $C X C l 3$ mRNA in the paired cancer and adjacent tissues of $38 \mathrm{CC}$ patients revealed that $\mathrm{CXCl3}$ was overexpressed in $\mathrm{CC}$; the IHC scores of cancer and adjacent normal tissues in 46 patients revealed that the $C X C L 3$ score for cancer tissues were higher than that 

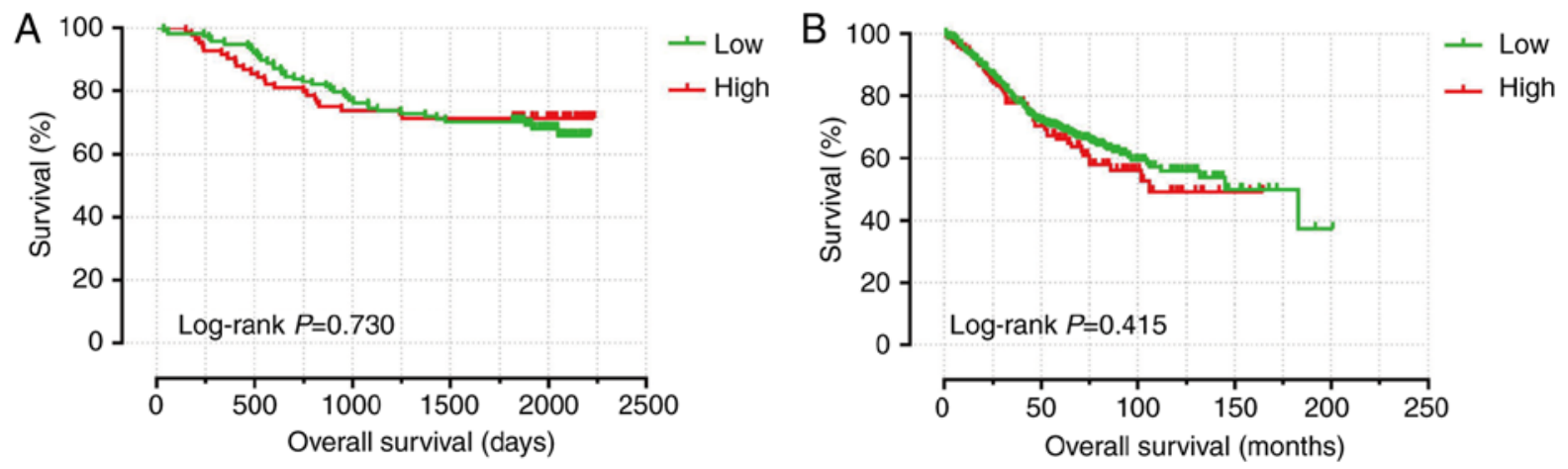

Figure 4. Kaplan-Meier curves for the survival of colon cancer patients with high and low CXCL3 gene expression levels. (A) Kaplan-Meier curve for the patient cohort from Guangxi Medical University (May 2012 to May 2013) and (B) Kaplan-Meier curve for the GSE40967 cohort. CXCL3, C-X-C motif chemokine ligand 3 .

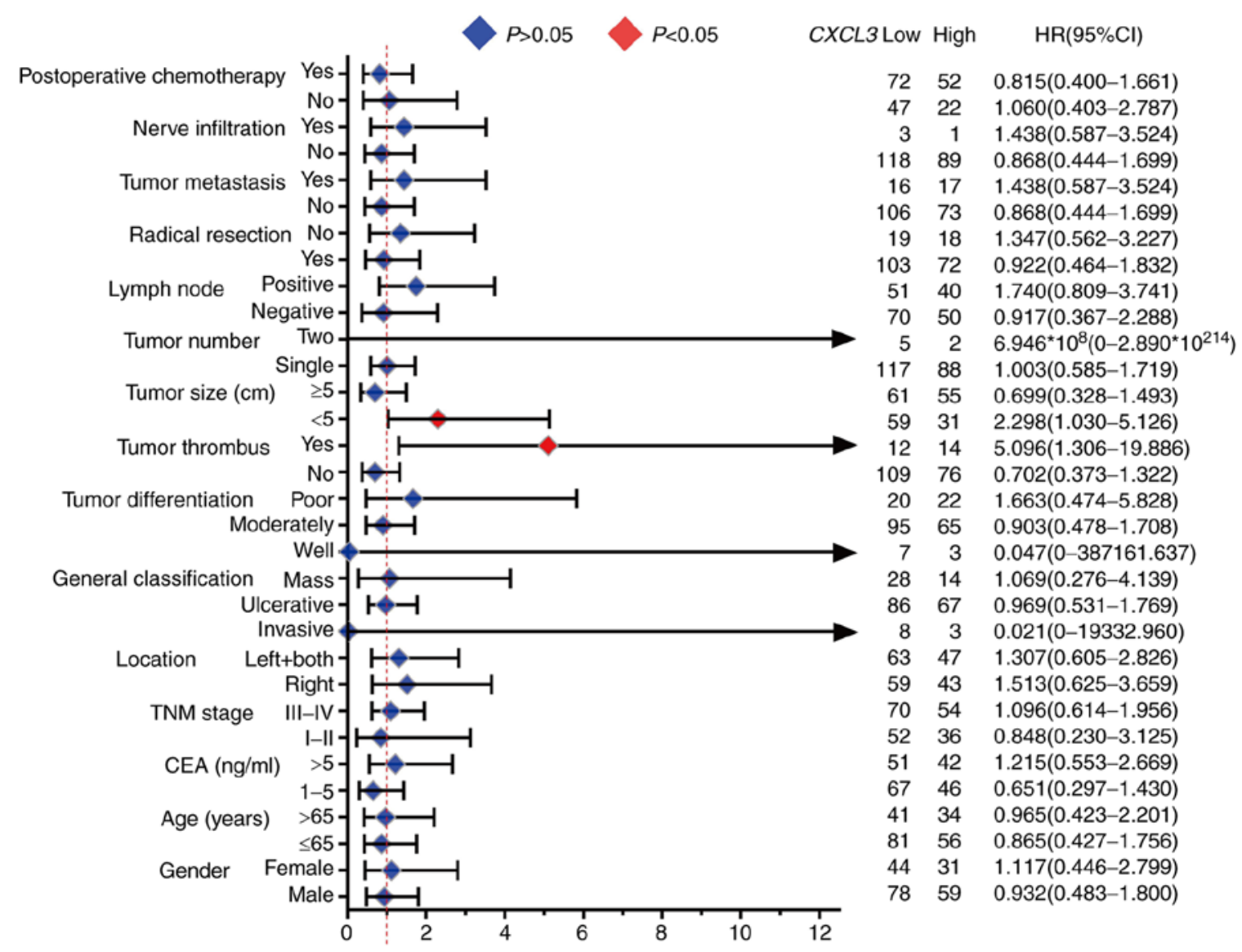

Figure 5. Forest plot of the stratified analysis of the association of $C X C L 3$ with OS for different characteristics in the colon cancer patient cohort from Guangxi Medical University. CXCL3, C-X-C motif chemokine ligand 3; TNM, tumor node metastasis; CEA, carcinoembryonic antigen.

for the adjacent tissues. These results are consistent with the results obtained using GEPIA. Therefore, the present study verified the overexpression of CXCL3 in CC tissues at both the genetic and protein levels, which indicates that $C X C L 3$ may be a potential marker for the diagnosis of CC.

Previous studies have found that overexpression of CXCL3 indicates poor prognosis, Specifically, hepatocellular carcinoma patients with higher CXCL3 expression have been observed to have a shorter survival time (32). In addition, shorter OS was observed in CRC patients with increased CXCL3 expression (10). In the current study of CC, similar results were obtained. In the multivariate analysis of the Guangxi Medical University cohort of 212 CC patients, although CXCL3 expression was not closely and directly connected with OS time, further subgroup analysis revealed that CXCL3 positive expression in patients who had a tumor diameter $<5 \mathrm{~cm}$ or a tumor embolus indicated poorer prognosis. A subsequent multivariate analysis of prognosis in the GEO cohort, which was performed to verify the results obtained from Guangxi Medical university cohort, found that CXCL3 gene expression was notably relevant to overall patient survival, and patients with high CXCL3 gene expression had 
Table II. Clinical and pathological parameters of 585 patients with colon cancer from the GSE40967 cohort.

\begin{tabular}{|c|c|c|c|c|}
\hline Variable & No. of patients & MST (months) & $\mathrm{OS}^{\mathrm{a}}, \mathrm{HR}(95 \% \mathrm{CI})^{\mathrm{b}}$ & Log-rank P-value \\
\hline Sex & & & & 0.066 \\
\hline Male & 322 & 112 & 1 & \\
\hline Female & 263 & 183 & $0.765(0.573-1.020)$ & \\
\hline Age (years) & & & & 0.010 \\
\hline$\leq 65$ & 228 & NA & 1 & \\
\hline$>65$ & 356 & 105 & $1.479(1.094-1.999)$ & \\
\hline Missing & 1 & & & \\
\hline TNM stage & & & & $<0.0001$ \\
\hline 0-II & 313 & 183 & 1 & \\
\hline III-IV & 270 & 105 & $1.774(1.335-2.358)$ & \\
\hline Missing & 2 & & & \\
\hline Location & & & & 0.584 \\
\hline Distal & 351 & 145 & 1 & \\
\hline Proximal & 232 & NA & $1.084(0.812-1.447)$ & \\
\hline Missing & 2 & & & \\
\hline Chemotherapy adjuvant & & & & 0.607 \\
\hline No & 326 & 183 & 1 & \\
\hline Yes & 240 & 145 & $0.926(0.690-1.243)$ & \\
\hline Missing & 19 & & & \\
\hline MMR status & & & & 0.397 \\
\hline dMMR & 77 & NA & 1 & \\
\hline pMMR & 459 & NA & $1.227(0.762-1.977)$ & \\
\hline Missing & 49 & & & \\
\hline CIMP status & & & & 0.589 \\
\hline Negative & 420 & 145 & 1 & \\
\hline Positive & 93 & NA & $1.115(0.751-1.656)$ & \\
\hline Missing & 72 & & & \\
\hline CIN status & & & & 0.170 \\
\hline Negative & 112 & NA & 1 & \\
\hline Positive & 369 & 145 & $0.770(0.529-1.121)$ & \\
\hline Missing & 104 & & & \\
\hline TP53 mutation & & & & 0.312 \\
\hline Mutant & 190 & 105 & 1 & \\
\hline Wild type & 161 & NA & $0.836(0.590-1.185)$ & \\
\hline Missing & 234 & & & \\
\hline \multicolumn{5}{|l|}{$K R A S$ mutation } \\
\hline Mutant & 217 & 132 & 1 & 0.037 \\
\hline Wild type & 328 & 145 & $0.736(0.551-0.983)$ & \\
\hline Missing & 40 & & & \\
\hline$B R A F$ mutation & & & & 0.689 \\
\hline M & 51 & NA & 1 & \\
\hline WT & 460 & 145 & $0.900(0.538-1.508)$ & \\
\hline Missing & 74 & & & \\
\hline CIT molecular subtype & & & & 0.002 \\
\hline $\mathrm{C} 1$ & 116 & 86 & 1 & \\
\hline $\mathrm{C} 2$ & 104 & NA & $0.722(0.447-1.165)$ & \\
\hline $\mathrm{C} 3$ & 74 & NA & $0.639(0.360-1.137)$ & \\
\hline $\mathrm{C} 4$ & 59 & 46 & $1.790(1.125-2.850)$ & \\
\hline $\mathrm{C} 5$ & 152 & 145 & $0.855(0.567-1.288)$ & \\
\hline C6 & 60 & 105 & $1.001(0.602-1.665)$ & \\
\hline Missing & 20 & & & \\
\hline
\end{tabular}


Table II. Continued.

\begin{tabular}{|c|c|c|c|c|}
\hline Variable & No. of patients & MST (months) & $\mathrm{OS}^{\mathrm{a}}, \mathrm{HR}(95 \% \mathrm{CI})^{\mathrm{b}}$ & Log-rank P-value \\
\hline CXCL3 & & & & 0.415 \\
\hline Low & 439 & 145 & 1 & \\
\hline High & 146 & 106 & $1.139(0.829-1.566)$ & \\
\hline
\end{tabular}

${ }^{a} \mathrm{OS}$ times were available for 579 patients; ${ }^{\text {b }} \mathrm{HR}$ and $95 \% \mathrm{CI}$ values were calculated using a univariate Cox proportional hazards regression model; ' log-rank P-values were calculated by the Kaplan-Meier method with a log-rank test. MST, median survival time; OS, overall survival time; TNM, tumor node metastasis; MMR, mismatch repair; dMMR deficient mismatch repair; pMMR, proficient mismatch repair; CIMP, CpG island methylator phenotype; CIN chromosomal instability; CIT, Cartes d'Identité des Tumeurs; CXCL3, C-X-C motif chemokine ligand 3.

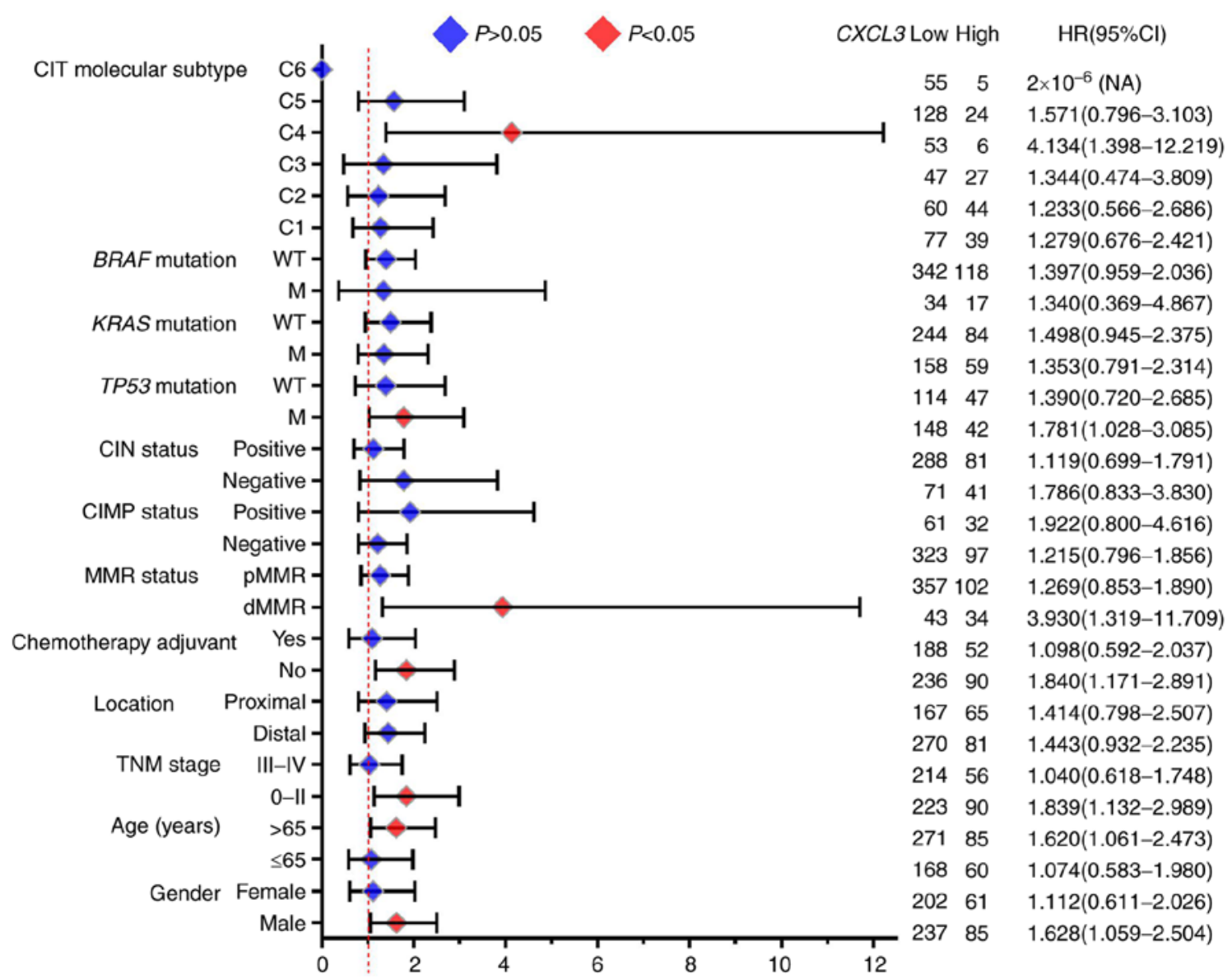

Figure 6. Forest plot of the stratified analysis of the association of $C X C L 3$ with OS for different characteristics for the GSE40967 cohort. CXCL3, C-X-C motif chemokine ligand 3; CIT, Cartes d'Identité des Tumeurs; CIN, chromosomal instability; CIMP, CpG island methylator phenotype; MMR, mismatch repair; dMMR, deficient mismatch repair; pMMR, proficient mismatch repair; TNM, tumor node metastasis.

shorter survival times. These results also suggest that $C X C L 3$ might be a candidate prognostic biomarker for $\mathrm{CC}$.

CXCL3 is considered to serve a major role in tumor initiation and invasion. The expression of CXCL3 in normal colon tissue is high, indicating that it plays a certain role in the physiological function of normal intestinal tissues, but is dysregulated in cancer, indicating that expression disorder of CXCL3 may be involved in the tumorigenesis of CC (33). To examine the potential mechanism of $C X C L 3$ in $\mathrm{CC}$, a genome-wide RNA sequencing dataset in GSEA was analyzed in the present study. The results indicated that the mechanism by which $C X C L 3$ affects $C C$ prognosis may involve biological processes and signaling pathways connected with DNA repair, cell cycle, apoptosis and P53 signaling. Previous studies have suggested an association between DNA repair and CRC development (34-36). Soreide et al (37) reported that cell cycle and apoptosis are associated with the prognosis of CRC. Numerous studies have reported a relationship between P53 and the development of CRC (38-40). However, to the best of our knowledge, the functional correlations of DNA repair, cell 

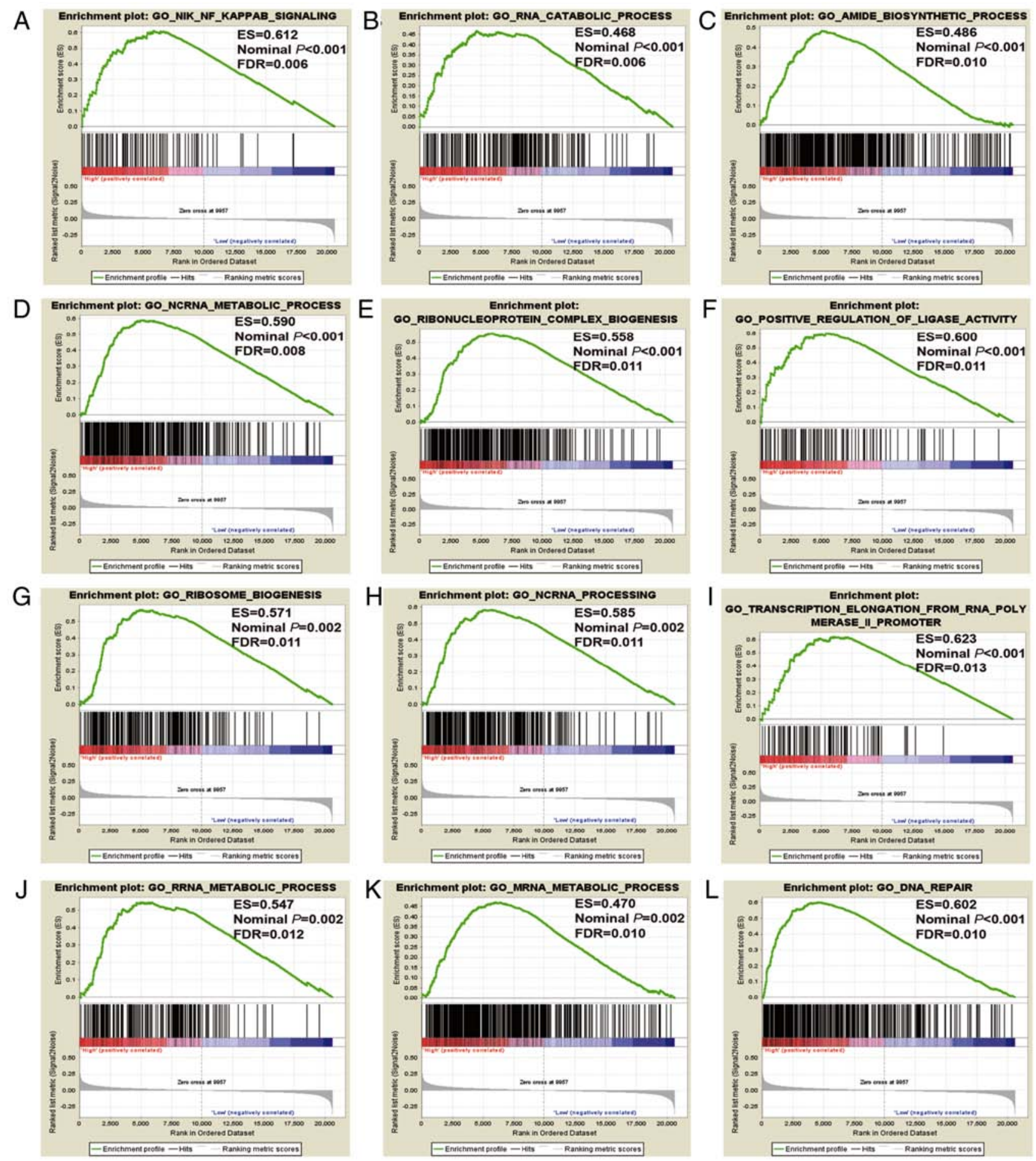

Figure 7. GSEA results of $C X C L 3$ in the GSE40967 cohort, based on a GO dataset. (A) NIK NF $\kappa B$ signaling, (B) RNA catabolic process, (C) amide biosynthetic process (D) ncRNA metabolic process, (E) ribonucleoprotein complex biogenesis, (F) positive regulation of ligase activity, (G) ribosome biogenesis, (H) ncRNA processing, (I) transcription elongation from RNA polymerase II promoter, (J) rRNA metabolic process, (K) mRNA metabolic process and (L) DNA repair. GSEA, gene set enrichment analysis; CXCL3, C-X-C motif chemokine ligand 3; ES, enrichment score; FDR, false discovery rate; ncRNA, non-coding RNA; rRNA, ribosomal RNA; mRNA, messenger RNA.

cycle, apoptosis and $P 53$ with $C X C L 3$ have not been previously reported. The GSEA of $C X C L 3$ in the present study supported the conclusion that $C X C L 3$ might affect CC via DNA repair, cell cycle, apoptosis and the P53 pathway. However, these hypotheses require further research for confirmation.

The present study used GSE40967 and Guangxi cohorts to analyze the prognostic value of CXCL3 in CC at the mRNA and protein levels. These two cohorts belong to retrospective cohort studies with a level of evidence of four, as defined on the basis of the Oxford Centre for Evidence-based Medicine-Levels of Evidence (41). However, the present study has certain limitations. The clinical information from the GEO database was incomplete, and information such as tumor size, histology, tumor differentiation, lymphatic invasion and venous invasion were unattainable 
A

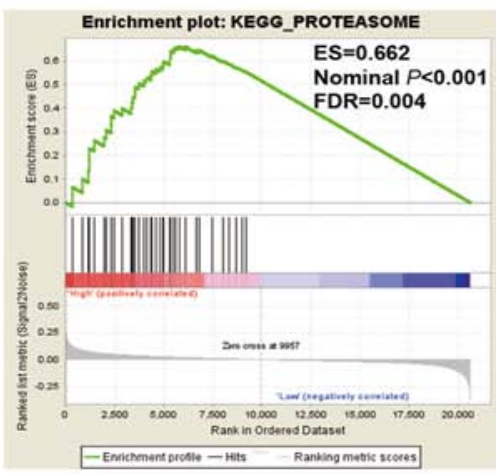

D

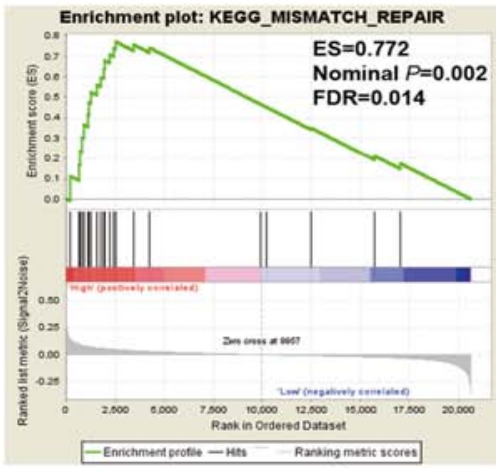

G
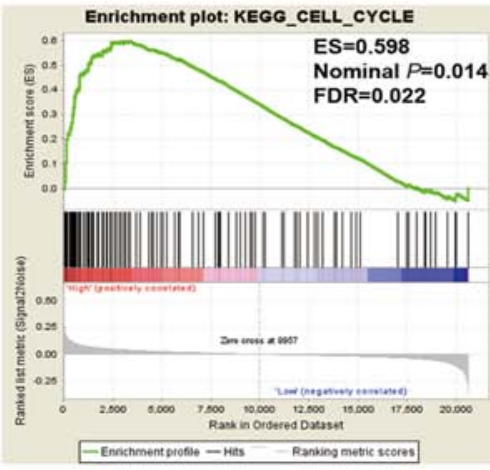

$J$

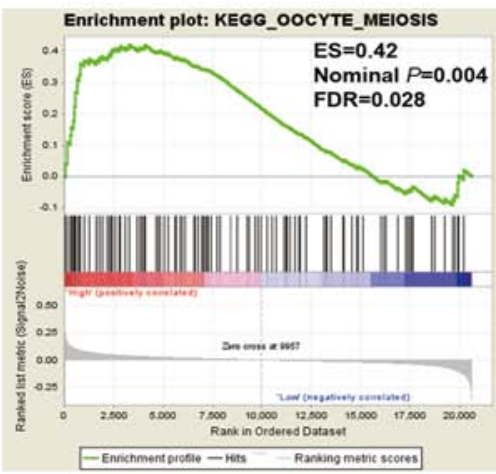

B

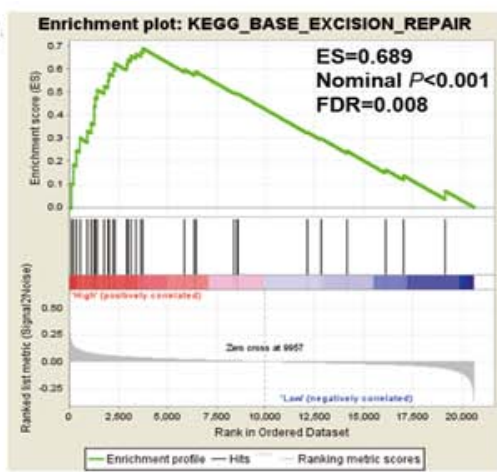

E

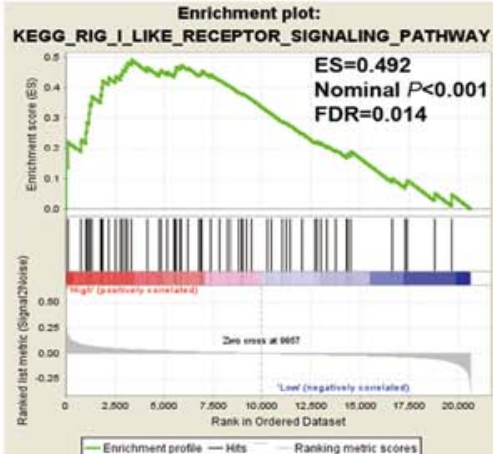

$\mathrm{H}$

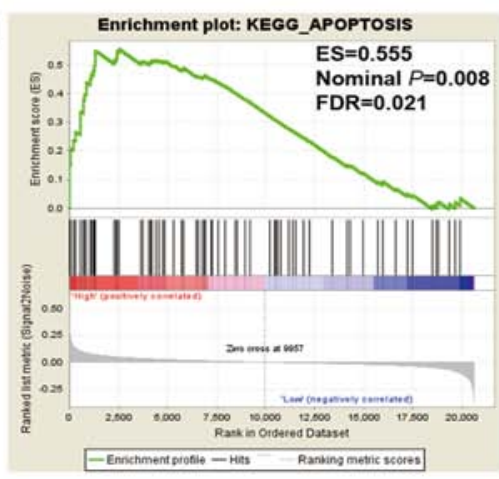

$\mathrm{K}$

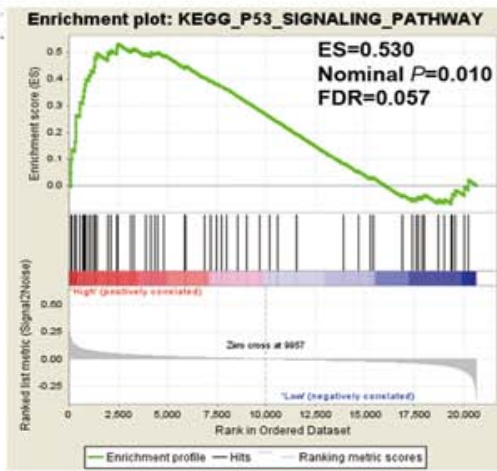

C

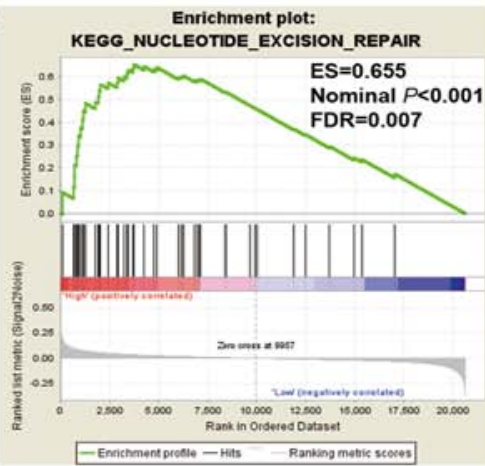

$\mathrm{F}$

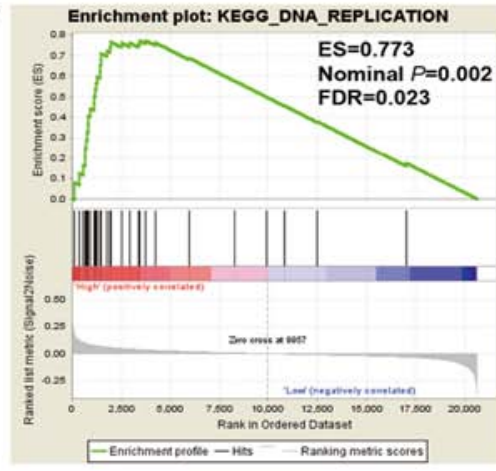

I Enrichment plot:

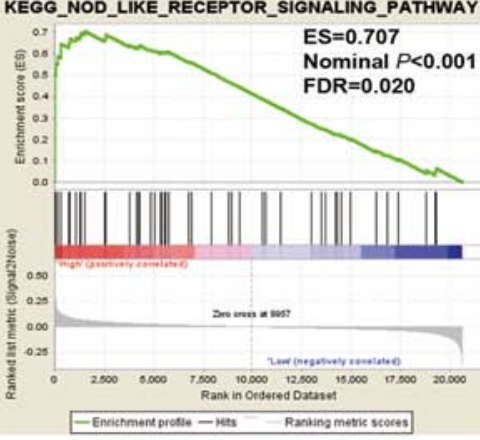

$\mathrm{L}$

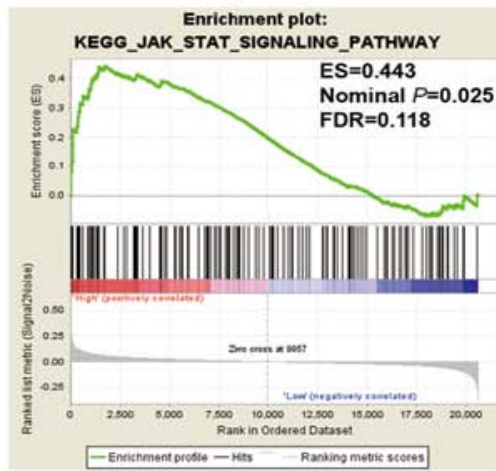

Figure 8. GSEA results of CXCL3 in the GSE40967 cohort, based on a KEGG dataset. (A) proteasome, (B) base excision repair, (C) nucleotide excision repair, (D) mismatch repair, (E) RIG I-like receptor signaling pathway, (F) DNA replication, (G) cell cycle, (H) apoptosis, (I) NOD-like receptor signaling pathway, (J) oocyte meiosis, (K) P53 signaling pathway, (L) JAK STAT signaling pathway. GSEA, gene set enrichment analysis; $C X C L 3$, C-X-C motif chemokine ligand 3; RIG I, retinoic acid-inducible gene-I; NOD, nucleotide-binding oligomerization domain; ES, enrichment score; FDR, false discovery rate.

from the GEO website. The results of this study also require validation in a larger sample population and in a multi-center, multi-regional and multi-ethnic population. Furthermore, in vitro and in vivo functional trials are needed to further explore the roles of $C X C L 3$ in CC initiation, development, metastasis, proliferation and angiogenesis. However, to the best of our knowledge, the current study is the first to discover the value of CXCL3 in the diagnosis and prognosis of CC, rather than CRC. Another advantage of this study is that, in addition to identifying the prognostic value of $C X C L 3$ in CC in large samples, a GEO genome-wide dataset was also used to explore prospective molecular mechanisms through the GSEA approach.

In conclusion, the present study demonstrated that $C X C L 3$ is not only considerably upregulated in tumor tissue but also has 
potential diagnostic value in patients with CC. Survival analysis in Guangxi Medical University and GEO cohorts suggested that CXCL3 may serve as a potential prognostic biomarker in CC. The prospective molecular mechanism identified by GSEA suggested that CXCL3 may influence the prognosis of CC through involvement in the regulation of DNA repair, cell cycle process, cell apoptosis process and P53 regulation pathways. However, these results require further verification using in vivo and in vitro experiments in future studies.

\section{Acknowledgements}

The authors would like to acknowledge the support (experimental environments and equipment) provided by the National Key Clinical Specialty Programs (General Surgery and Oncology) and Key Laboratory of Early Prevention and Treatment for Regional High-Incidence-Tumor (Guangxi Medical University), Ministry of Education, China. In addition, the authors also like to acknowledge the helpful comments on this paper received from the reviewers.

\section{Funding}

This study was supported in part by the 2018 Innovation Project of Guangxi Graduate Education (grant no. YCBZ2018036). This study was also supported by the Graduate Course Construction Project of Guangxi Medical University (grant nos. YJSB2017008 and YJSA2017014).

\section{Availability of data and materials}

The analyzed datasets generated during the study are available from Gene Expression Omnibus (https://www.ncbi.nlm.nih. gov/geo/), and the datasets for the colon cancer cohort from the First Affiliated Hospital of Guangxi Medical University used and/or analyzed during the current study are available from the corresponding author on reasonable request.

\section{Authors' contributions}

GTR and YZG wrote the manuscript. GTR and FG made substantial contributions to the conception, design and intellectual content of the study. GTR, YZG, XWL, SW, WH, XKW, GZZ and CL made key contributions to the analysis and interpretation of data. All authors read and approved the final manuscript.

\section{Ethics approval and consent to participate}

All patients signed an informed consent form, and the experimental protocol was approved by the Ethics Committee of the First Affiliated Hospital of Guangxi Medical University [No. 2019(KY-E-001)].

\section{Patient consent for publication}

Not applicable.

\section{Competing interests}

The authors declare that they have no competing interests.

\section{References}

1. Bray F, Ferlay J, Soerjomataram I, Siegel RL, Torre LA and Jemal A: Global cancer statistics 2018: GLOBOCAN estimates of incidence and mortality worldwide for 36 cancers in 185 countries. CA Cancer J Clin 68: 394-424, 2018.

2. Chen W, Zheng R, Baade PD, Zhang S, Zeng H, Bray F, Jemal A, $\mathrm{Yu}$ XQ and He J: Cancer statistics in China, 2015. CA Cancer J Clin 66: 115-132, 2016.

3. Garborg K: Colorectal cancer screening. Surg Clin North Am 95: 979-989, 2015.

4. Pita-Fernández S, González-Sáez L, López-Calviño B, Seoane-Pillado T, Rodríguez-Camacho E, Pazos-Sierra A, González-Santamaría P and Pértega-Díaz S: Effect of diagnostic delay on survival in patients with colorectal cancer: A retrospective cohort study. BMC Cancer 16: 664, 2016.

5. Aran V, Victorino AP, Thuler LC and Ferreira CG: Colorectal Cancer: Epidemiology disease mechanisms and interventions to reduce onset and mortality. Clin Colorectal Cancer 15: 195-203, 2016.

6. Clough $\mathrm{E}$ and Barrett $\mathrm{T}$ : The gene expression omnibus database. Methods Mol Biol 1418: 93-110, 2016.

7. Ahuja SK and Murphy PM: The CXC chemokines growth-regulated oncogene (GRO) alpha, GRObeta, GROgamma, neutrophil-activating peptide-2, and epithelial cell-derived neutrophil-activating peptide-78 are potent agonists for the type B, but not the type A, human interleukin- 8 receptor. J Biol Chem 271: 20545-20550, 1996

8. Smith DF, Galkina E, Ley K and Huo Y: GRO family chemokines are specialized for monocyte arrest from flow. Am J Physiol Heart Circ Physiol 289: H1976-H1984, 2005.

9. Doll D, Keller L, Maak M, Boulesteix AL, Siewert JR, Holzmann B and Janssen KP: Differential expression of the chemokines GRO-2, GRO-3, and interleukin-8 in colon cancer and their impact on metastatic disease and survival. Int J Colorectal Dis 25: 573-581, 2010.

10. Xiong Y, You W, Wang R, Peng L and Fu Z: Prediction and validation of hub genes associated with colorectal cancer by integrating PPI network and gene expression data. Biomed Res Int 2017: 2421459, 2017.

11. Magalhaes B, Peleteiro B and Lunet N: Dietary patterns and colorectal cancer: Systematic review and meta-analysis. Eur J Cancer Prev 21: 15-23, 2012.

12. Rebbeck TR, Devesa SS, Chang BL, Bunker $\mathrm{CH}$, Cheng I, Cooney K, Eeles R, Fernandez P, Giri VN, Gueye SM, et al: Global patterns of prostate cancer incidence, aggressiveness, and mortality in men of african descent. Prostate Cancer 2013: $560857,2013$.

13. Rong M, He R, Dang Y and Chen G: Expression and clinicopathological significance of miR-146a in hepatocellular carcinoma tissues. Ups J Med Sci 119: 19-24, 2014.

14. Dai J, Wu H, Zhang Y, Gao K, Hu G, Guo Y, Lin C and Li X: Negative feedback between TAp63 and Mir-133b mediates colorectal cancer suppression. Oncotarget 7: 87147-87160, 2016.

15. Amin MB, Edge S, Greene F, Byrd DR, Brookland RK, Washington MK, Gershenwald JE, Compton CC, Hess KR, Sullivan DC, et al: AJCC Cancer Staging Manual (8th Edition). Springer, Chicago, IL, p20, 2017.

16. Zhang Y, Luo J, He R, Huang W, Li Z, Li P, Dang Y, Chen G and $\mathrm{Li}$ S: Expression and clinicopathological implication of DcR3 in lung cancer tissues: A tissue microarray study with 365 cases. Onco Targets Ther 9: 4959-4968, 2016.

17. Uhlen M, Fagerberg L, Hallstrom BM, Lindskog C, Oksvold P, Mardinoglu A, Sivertsson A, Kampf C, Sjostedt E, Asplund A, et al: Proteomics. Tissue-based map of the human proteome. Science 347: 1260419, 2015.

18. Tang Z, Li C, Kang B, Gao G and Zhang Z: GEPIA: A web server for cancer and normal gene expression profiling and interactive analyses. Nucleic Acids Res 45: W98-W102, 2017.

19. Marisa L, de Reynies A, Duval A, Selves J, Gaub MP, Vescovo L, Etienne-Grimaldi MC, Schiappa R, Guenot D, Ayadi M, et al: Gene expression classification of colon cancer into molecular subtypes: Characterization, validation, and prognostic value. PLoS Med 10: e1001453, 2013.

20. Subramanian A, Tamayo P, Mootha VK, Mukherjee S, Ebert BL, Gillette MA, Paulovich A, Pomeroy SL, Golub TR, Lander ES, et al: Gene set enrichment analysis: A knowledge-based approach for interpreting genome-wide expression profiles. Proc Natl Acad Sci USA 102: 15545-15550, 2005. 
21. Benjamini $\mathrm{Y}$ and Hochberg $\mathrm{Y}$ : Controlling the false discovery rate: A practical and powerful approach to multiple testing. J Royal Stat Soc Series B (Methodological) 57: 289-300, 1995.

22. Reiner A, Yekutieli D and Benjamini Y: Identifying differentially expressed genes using false discovery rate controlling procedures. Bioinformatics 19: 368-375, 2003.

23. O'Donovan N, Galvin M and Morgan JG: Physical mapping of the CXC chemokine locus on human chromosome 4. Cytogenet Cell Genet 84: 39-42, 1999.

24. Airoldi I and Ribatti D: Regulation of angiostatic chemokines driven by IL-12 and IL-27 in human tumors. J Leukoc Biol 90: 875-882, 2011.

25. Simpson KJ, Henderson NC, Bone-Larson CL, Lukacs NW, Hogaboam CM and Kunkel SL: Chemokines in the pathogenesis of liver disease: So many players with poorly defined roles. Clin Sci (Lond) 104: 47-63, 2003.

26. Luan J, Shattuck-Brandt R, Haghnegahdar H, Owen JD, Strieter R, Burdick M, Nirodi C, Beauchamp D, Johnson KN and Richmond A: Mechanism and biological significance of constitutive expression of MGSA/GRO chemokines in malignant melanoma tumor progression. J Leukoc Biol 62: 588-597, 1997.

27. See AL, Chong PK, Lu SY and Lim YP: CXCL3 is a potential target for breast cancer metastasis. Curr Cancer Drug Targets 14: 294-309, 2014

28. Gui SL, Teng LC, Wang SQ, Liu S, Lin YL, Zhao XL, Liu L, Sui HY, Yang Y, Liang LC, et al: Overexpression of CXCL3 can enhance the oncogenic potential of prostate cancer. Int Urol Nephrol 48: 701-709, 2016.

29. Li A, Varney ML and Singh RK: Constitutive expression of growth regulated oncogene (gro) in human colon carcinoma cells with different metastatic potential and its role in regulating their metastatic phenotype. Clin Exp Metastasis 21: 571-579, 2004

30. Farquharson AJ, Steele RJ, Carey FA and Drew JE: Novel multiplex method to assess insulin, leptin and adiponectin regulation of inflammatory cytokines associated with colon cancer. Mol Biol Rep 39: 5727-5736, 2012.

31. Kowalczuk O, Burzykowski T, Niklinska WE, Kozlowski M, Chyczewski L and Niklinski J: CXCL5 as a potential novel prognostic factor in early stage non-small cell lung cancer: Results of a study of expression levels of 23 genes. Tumour Biol 35: 4619-4628, 2014

32. Zhang L, Li H, Ge C, Zhao F, Tian H, Chen T, Jiang G, Xie H, Cui Y, Yao M, et al: CXCL3 contributes to CD133(+) CSCs maintenance and forms a positive feedback regulation loop with CD133 in HCC via Erk1/2 phosphorylation. Sci Rep 6: 27426 , 2016.
33. Fagerberg L, Hallstrom BM, Oksvold P, Kampf C, Djureinovic D, Odeberg J, Habuka M, Tahmasebpoor S, Danielsson A, Edlund $\mathrm{K}$, et al: Analysis of the human tissue-specific expression by genome-wide integration of transcriptomics and antibody-based proteomics. Mol Cell Proteomics 13: 397-406, 2014.

34. Dörsam B, Seiwert N, Foersch S, Stroh S, Nagel G, Begaliew D, Diehl E, Kraus A, McKeague M, Minneker V, et al: PARP-1 protects against colorectal tumor induction, but promotes inflammation-driven colorectal tumor progression. Proc Natl Acad Sci USA 115: E4061-E4070, 2018.

35. AlDubayan SH, Giannakis M, Moore ND, Han GC, Reardon B, Hamada T, Mu XJ, Nishihara R, Qian Z, Liu L, et al: Inherited DNA-repair defects in colorectal cancer. Am J Hum Genet 102: 401-414, 2018.

36. Aggarwal N, Donald ND, Malik S, Selvendran SS, McPhail MJ and Monahan KJ: The association of low-penetrance variants in DNA repair genes with colorectal cancer: A systematic review and meta-analysis. Clin Transl Gastroenterol 8: e109, 2017.

37. Soreide K, Buter TC, Janssen EA, Gudlaugsson E, Skaland I, Korner H and Baak JP: Cell-cycle and apoptosis regulators (p16INK4A, p21CIP1, beta-catenin, survivin, and hTERT) and morphometry-defined MPECs predict metachronous cancer development in colorectal adenoma patients. Cell Oncol 29: 301-313, 2007.

38. Noda M, Okayama H, Kofunato Y, Chida S, Saito K, Tada T, Ashizawa M, Nakajima T, Aoto K, Kikuchi T, et al: Prognostic role of FUT8 expression in relation to p53 status in stage II and III colorectal cancer. PLoS One 13: e0200315, 2018.

39. Wu Y, Li Y, Zhao X, Dong D, Tang C, Li E and Geng Q: Combined detection of the expression of $\mathrm{Nm} 23-\mathrm{H} 1$ and p53 is correlated with survival rates of patients with stage II and III colorectal cancer. Oncol Lett 13: 129-136, 2017.

40. Katkoori VR, Manne U, Chaturvedi LS, Basson MD, Haan P, Coffey D and Bumpers HL: Functional consequence of the p53 codon 72 polymorphism in colorectal cancer. Oncotarget 8: 76574-76586, 2017.

41. Howick J, Chalmers I, Glasziou P, Greenhalgh T, Heneghan C, Liberati A, Moschetti I, Phillips B and Thornton H: The 2011 Oxford CEBM Levels of Evidence (Introductory Document). Oxford Centre for Evidence-Based Medicine. http://www.cebm. net/index.aspx?o $=5653$.

This work is licensed under a Creative Commons Attribution-NonCommercial-NoDerivatives 4.0 International (CC BY-NC-ND 4.0) License. 